\title{
REGULAÇÃO DAS POLÍTICAS EDUCACIONAIS NA AMÉRICA LATINA E SUAS CONSEQÜÊNCIAS PARA OS TRABALHADORES DOCENTES*
}

\author{
Dalila Andrade Oliveira**
}

\begin{abstract}
RESUMO: $\mathrm{O}$ artigo procura discutir a atual regulação das políticas educativas na América Latina e suas consequiências sobre os trabalhadores docentes. Parte da premissa de que um novo modelo de regulação de políticas educativas emergiu muito recentemente em conseqüência do ciclo de reformas que muitos países conheceram nos seus sistemas educacionais a partir dos anos de 1990. As reflexôes trazidas neste artigo são resultantes de pesquisa em desenvolvimento sobre o tema, mais especificamente de levantamento documental e revisão bibliográfica realizados em estágio pós-doutoral no Laboratório de Políticas Públicas da Universidade Estadual do Rio de Janeiro. $\mathrm{O}$ artigo procura caracterizar sumariamente o que seria o debate em torno de uma nova regulação das políticas educativas na América Latina e suas conseqüências para os trabalhadores docentes, a partir de alguns elementos que permitem conhecer a especificidade deste subcontinente, porém buscando interpretar tais elementos à luz de contribuições de autores que vêm se debruçando sobre o assunto partindo de diferentes contextos nacionais.
\end{abstract}

Palavras-chave: Trabalho docente. Política educacional. Educação. Regulação. América Latina.

* As discussões apresentadas neste artigo resultam de pesquisa realizada em estágio de pósdoutoramento no Laboratório de Políticas Públicas da Universidade Estadual do Rio de Janeiro (UERJ), sob a supervisão do prof. dr. Emir Sader, durante o primeiro semestre deste ano, com o financiamento do CNPq.

** Socióloga, doutora em educação pela Universidade de São Paulo (USP) e professora do Programa de Pós-Graduação em Educação e do Departamento de Administração Escolar da Faculdade de Educação da Universidade Federal de Minas Gerais (UFMG); pesquisadora do CNPq. E-mail: dalila@fae.ufmg.br

Educ. Soc., Campinas, vol. 26, n. 92, p. 753-775, Especial - Out. 2005

Disponível em <http://www.cedes.unicamp.br> 
Regulação das políticas educacionais na América Latina e suas conseqüências para...

\title{
Regulation of edUCATional policies in Latin AMERica AND ITS CONSEQUENCES FOR TEACHING WORKERS
}

\begin{abstract}
The present paper discusses the current regulation of the educational policies in Latin America and its consequences for teaching workers. It assumes that a new model of regulation of educational policies has recently emerged as a consequence of the cycle of reforms experienced by many countries since the 1990s. The considerations brought here are the result of a research, more precisely of a document survey and bibliographic revision, on this theme that I developed as part of a post-doctorate scholarship at the Laboratory of Public Policies of the Universidade Estadual do Rio de Janeiro (UERJ). This text tries to characterize the debate on a new regulation of the educational policies in Latin America and its consequences for the teaching workers based on some elements allowing us to know the specificities of this subcontinent, although seeking to interpret such elements in the light of the contribution of authors who have studied the subject in various national contexts.
\end{abstract}

Key words: Teaching work. Educational policy. Education. Regulation. Latin America.

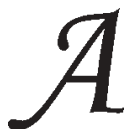

$s$ discussões sobre o atual modelo de regulação das políticas educativas emergiram muito recentemente, em conseqüência do ciclo de reformas que muitos países conheceram nos seus sistemas educacionais, a partir dos anos de 1990. No Brasil, até muito pouco tempo atrás essa discussão, assim nomeada, inexistia. Os primeiros trabalhos que empregam a expressão "regulação das políticas educativas" começam a aparecer só na presente década e ainda são muito poucos. ${ }^{1}$ Neste sentido, a iniciativa deste dossiê, organizado pela revista Educação \& Socieda$d e$, traz importante contribuição a esse debate. O presente artigo pretende contribuir nessa discussão trazendo mais indagações do que formulações conclusivas e apresentando parte do que têm sido as reflexões surgidas no desenvolvimento desta pesquisa, ainda por concluir. As questôes aqui apresentadas se baseiam em levantamento documental e revisão bibliográfica realizados no primeiro semestre deste ano e, por esta razão, carecem de melhor tratamento e maior aprofundamento. Portanto, a intenção, por ora, é tentar caracterizar sumariamente o que seria o debate em torno de uma nova regulação das políticas educativas na América Latina e suas conseqüências para os trabalhadores docentes, a partir de alguns elementos que permitem conhecer a especificidade deste subcontinente, 
porém buscando interpretar tais elementos à luz de contribuições de autores que vêm se debruçando sobre o assunto partindo de diferentes contextos nacionais.

Uma primeira e relevante tarefa é buscar uma melhor definição do que se entende por regulação das políticas educativas. Para tanto, exige-se o conhecimento dos sentidos atribuídos ao termo "regulação". Embora tal termo seja amplamente utilizado como conceito no âmbito da economia e da sociologia, desde os primórdios dessas disciplinas, ele começa a vulgarizar-se a partir dos processos de privatização de empresas públicas, que ocorreram com as reformas de Estado implementadas nas últimas duas décadas do século passado e, no caso brasileiro, mais especificamente durante o governo do presidente Fernando Henrique Cardoso. Com a privatização de empresas estatais responsáveis por serviços prioritários, tais como energia elétrica, água, gás, telefonia, entre outros, são criadas as agências de regulação, que têm por objetivo justamente controlar a oferta e o atendimento às demandas da população por esses serviços.

A regulação tem sido objeto de grandes discussóes nos meios políticos, mais especificamente governamentais, envolvendo os poderes constituídos, os empresários e as organizaçōes de usuários de serviços regulados, bem como outros setores da sociedade. São exemplos do crescimento desse debate a realização de congressos nacionais sobre o tema, fóruns mundiais e a criação da Associação Brasileira de Agências de Regulação (ABAR). O principal debate nesses meios parece girar em torno do papel das agências reguladoras como entes de Estado e das relaçóes entre os prestadores de serviços públicos e seus usuários. As tensões surgem na definição do papel primordial dessas agências reguladoras e no estabelecimento do controle social sobre os serviços que pretendem regular, bem como na maior ou menor autonomia e independência dessas agências, em relação ao governo e às concessionárias/prestadoras do serviço público. $\mathrm{O}$ termo "regulação", amplamente conhecido e debatido na área econômica, ganha, assim, maior vigor no Brasil a partir do processo de reforma do Estado, conforme já comentado. A idéia alcança todos os setores, envolvendo desde a regulação da energia, dos meios climáticos, dos alimentos, dos meios de comunicação, entre outros serviços essenciais, até a imprensa. Contudo, é importante observar que, no âmbito educacional, esta discussão ainda se encontra restrita aos meios acadêmicos. Tal observação vem no sentido de ressaltar que não nos encontramos em face de um pro- 
Regulação das políticas educacionais na América Latina e suas conseqüências para...

cesso de retirada explícita do Estado da oferta educacional, como nos exemplos anteriormente referidos, ainda que tenhamos alguns indícios desse tipo de orientação política, como é o caso do Programa Universidade para Todos (PROUNI), ${ }^{2}$ em que o Estado financia o atendimento público pela via privada, mantendo-se como elemento regulador do processo.

A regulação na economia é em geral vista como algo necessário às relaçôes de mercado, no sentido de coibir os monopólios, de controlar preços e condições de oferta e atendimento aos usuários. Esse processo, conhecido no Brasil a partir de então, também foi vivido por muitos países que tiveram seus Estados reformados. As reformas de Estado que a maioria dos países ocidentais conheceu a partir dos anos de 1980 vieram como corolário do processo de globalização. $\mathrm{Na}$ realidade, trata-se de um processo mais amplo de mudança econômica, política e cultural a que o mundo assistiu nas últimas décadas e que tem forjado novas formas de gestão econômica e controle social. As noções de governabilidade e governança nunca estiveram tão em voga como no momento em que as tradicionais instituições de poder sofrem pressóes no sentido de se desterritorializarem. A assunção de novas formas de organização dos mercados, de novas institucionalidades, como a Comunidade Européia, o Mercosul, Davos, Seattle, é exemplo da nova acomodação de poder que dá lugar a formas pluricentradas de formulação e decisão políticas - a novos modos de regulação.

Nesse contexto, o que se vem entendendo por regulação social são os aspectos relacionados à proteção dos interesses públicos, tais como saúde, segurança, meio ambiente, educação, ou seja, aqueles que podem pôr em risco a coesão social.

Neste sentido, a regulação do trabalho é um importante foco, já que o modelo de regulação social até então em vigor estava centrado na regulamentação do trabalho, na sua transformação em emprego e, conseqüentemente, em promessa de futuro e condição permanente e estável na vida para os que não detêm propriedades. A emergência de novos modelos de regulação da vida social tem resultado em desregulação do mercado de trabalho, maior flexibilização das relações de emprego, perda da estabilidade em alguns setores, bem como terceirização e precarização das condições de trabalho. Ou seja, para a maioria da população, esses novos processos de regulação têm representado a perda da estabilidade, da seguridade e, principalmente, da expectativa de futuro. 
Robert Castel (1999), discutindo as transformações sociais advindas do processo anteriormente mencionado, caracteriza-as como um questionamento da função integradora do trabalho hoje na sociedade. Para ele, o sistema de proteções e garantias sociais vinculadas ao trabalho tem sido gradativamente desmontado, chegando a "um processo de precarização que atinge as situaçóes do trabalho, no sentido da sua remercantilização e de soluçõos na ordem do mercado, como efeito particular da globalização" (p. 166-167).

Tal contexto interfere significativamente na educação: os sistemas escolares, que durante o século XX se organizaram em torno das demandas apresentadas pelo mercado de trabalho, pelas exigências produtivas e pela lógica de uma sociedade estruturada entre os que trabalham e os que exploram o trabalho, vêem-se ameaçados em sua própria racionalidade. A mobilidade social, até então garantida por meio da escolaridade, como condição para o emprego formal e regulamentado, tem sua eficácia comprometida na medida em que a confiança no futuro é estremecida. Ao mesmo tempo observa-se uma adequação dos discursos educativos a esse novo contexto, apresentando a importância da educação na busca por soluções alternativas à sobrevivência nesta sociedade em que já não há empregos para a maioria. ${ }^{3}$ Os sistemas escolares passam a sofrer mudanças consoantes à nova regulação social, a despeito do pouco que se sabe a esse respeito. Tais mudanças repercutem também sobre a regulação das políticas educativas.

A escola pública como agência estatal, tão presente em todos os espaços geográficos - nos meios urbanos e rurais, nos grandes centros e nas periferias, constituindo-se muitas vezes como a única presença do Estado entre determinadas populações, na maioria dos países latino-americanos, reveste-se de importante papel nesse contexto.

\section{Nova regulação capitalista e crise de paradigmas}

A referência primordial deste estudo, com relação ao conceito de regulação, é buscada no trabalho de Aglieta (1979), que nos ensina que estudar um modo de produção é colocar a descoberto quais são as relações determinantes que se reproduzem nas e pelas transformações sociais, verificar as formas sob as quais se realizam e discutir as causas em que essa reprodução se vê acompanhada de rupturas em diferentes pontos do 
Regulação das políticas educacionais na América Latina e suas conseqüências para...

sistema social. Por isso, considera que falar sobre a regulação de um modo de produção é tentar expressar, mediante leis gerais, como se reproduz a estrutura determinante de uma sociedade (Aglieta, 1979, p. 4).

Boaventura de Sousa Santos (2005), em livro recentemente publicado, aborda o tema da mudança nos padróes de regulação e as perspectivas (ou a ausência delas) de contraposição a esses processos, rumo à emancipação social. O autor identifica uma tensão atual entre regulação social e emancipação social. Nas suas palavras:

Tenho vindo a afirmar que o paradigma da modernidade se baseia numa tensão dialéctica entre regulação social e emancipação social, a qual está presente, mesmo que de modo diluído, na divisa positivista "ordem e progresso". Neste final de século, esta tensão deixou de ser uma tensão criativa. A emancipação deixou de ser o outro da regulação para se tornar no duplo da regulação. Enquanto, até finais dos anos de 1960, as crises de regulação social suscitavam o fortalecimento das políticas emancipatórias, hoje a crise da regulação social - simbolizada pela crise do Estado regulador e do Estado-Providência - e a crise da emancipação social - simbolizada pela crise da revolução social e do socialismo como paradigma da transformação social radical - são simultâneas e alimentam-se uma da outra. A política dos direitos humanos, que foi simultaneamente uma política reguladora e uma política emancipadora, está armadilhada nesta dupla crise, ao mesmo tempo em que é sinal do desejo de a ultrapassar. (Santos, 2002, p. 1)

O autor considera que a ciência em geral e as ciências sociais em especial atravessam hoje uma profunda crise de confiança epistemológica. As promessas que legitimaram o privilégio epistemológico do conhecimento científico a partir do século XIX - as promessas da paz e da racionalidade, da liberdade e da igualdade, do progresso e da partilha do progresso - não só não se realizaram, nem sequer no centro do sistema mundial, como se transformaram, nos países do Terceiro Mundo, na ideologia legitimadora da subordinação ao imperialismo ocidental. Observa que "em nome da ciência moderna destruíram-se muitos conhecimentos e ciências alternativas e humilharam-se os grupos sociais que neles se apoiavam para prosseguir as suas vias próprias autônomas de desenvolvimento" (Santos, 2002, p. 2).

Para o autor é hoje, mais do que nunca, evidente que o universalismo da ciência moderna é um particularismo ocidental cuja peculiaridade consiste em ter poder para definir como particulares locais, contex- 
tuais e situacionais os conhecimentos que com ela rivalizam. Daqui decorre a constatação de que houve e há outras ciências e outras modernidades não-ocidentais e muitos outros conhecimentos que se validam por outros critérios que não o de serem científicos ou de serem modernos. Fredric Jameson (2005), em uma perspectiva bastante distinta da apresentada por Boaventura de Sousa Santos, vai nos trazer importantes contribuições à análise do que poderíamos considerar a atual crise de paradigma nas ciências sociais trazida com a crise (ou o suposto fim) da modernidade, demonstrando como a crítica pós-moderna é em si moderna. Para Jameson, o ressurgimento, na filosofia política, de certos tópicos que não são do nosso tempo, tais como: a Constituição e a cidadania, a Sociedade Civil e a representação parlamentar, que foram tópicos marcantes no século XVIII, indicam-nos que nada "foi aprendido dos desafios do século revolucionário, que confrontou o pensamento burguês sobre o Estado com as ressentidas contradições de classe e do ser social coletivo" (Jameson, 2005, p. 10).

O que o autor parece nos apontar é que a crítica pós-moderna, que se apresenta como a ruptura com uma forma racional, hierárquica e padronizada de pensar, emerge "ao mesmo tempo em que uma antiga economia política avança aos tropeços, como uma sombra, e nos oferece um prodigioso desenvolvimento novo, ou seja, a reinvenção do mercado, algo tão excitante quanto a reinvenção da roda" (Idem, ibid., p. 11). O tom irônico do autor demonstra sua crítica e intolerância ao que considera a retórica da pós-modernidade que se afirma na defesa do caráter descentralizado, aleatório, heterogêneo e múltiplo das relações, na revalorização das particularidades, na mistura de estilos, no reconhecimento às diferenças. Para Jameson, trata-se de uma retórica, no sentido de que há ausência de correspondência com o real, operando ao nível do fetiche. Para ele, o fetiche da diferença no pós-modernismo confunde seus limites com o fetiche do novo, característico da modernidade. O conceito de modernidade está intimamente relacionado à idéia de novo e de presente, conseqüentemente, de ruptura e periodização. O termo moderno, historicamente, passa a ser utilizado como referência ao momento presente, diferenciando-se do passado e, neste sentido, indicando sempre uma idéia de periodização. Faz parte da narrativa modernista a historicidade e a noção de periodização. Ainda segundo Jameson, a modernidade significa sempre estabelecer e postular uma data e um começo, por isso as noções de ruptura e história sempre estiveram presen- 
Regulação das políticas educacionais na América Latina e suas conseqüências para...

tes no pensamento moderno. As críticas à periodização, à racionalização, tomadas como características modernas, põem em questão uma crise de paradigma, segundo afirma o mesmo autor:

Todos os temas requisitados, geralmente, como modos de identificar o moderno - a autoconsciência ou a reflexividade, a atenção maior à linguagem, ou à representação, a materialidade da superfície pintada, e por aí afora -, todos esses aspectos constituem em si mesmos meros pretextos para a operação da reescritura e para assegurar o efeito de assombro e de convicção adequado ao registro de uma mudança de paradigma. Isso não quer dizer que aqueles aspectos ou temas sejam fictícios ou irreais; o que se afirma, simplesmente, é a prioridade da operação da reescritura sobre as supostas intuições da análise histórica. (Idem, ibid., p. 48)

Por que falar em crise de paradigma para referenciar analiticamente a discussão em torno da regulação das políticas educacionais? Por que um recuo tão distante para se chegar a um tema de aparência tão trivial e cotidiana? Uma abordagem da nova regulação das políticas educativas, que busque apresentar novos elementos e trazer à luz aspectos que possam fugir do lugar-comum da descrição dos fatos e da lamúria freqüente sobre as mazelas do desenvolvimento capitalista periférico que couberam aos países do Terceiro Mundo e em especial à realidade latino-americana, exige situála epistemologicamente. Relacionar tal processo ao debate em torno das novas formas de pensar o mundo, de estruturar o pensamento e discutir em que medida as evidências empíricas desta nova regulação nos permitem identificar o que há de concreto e de retórica nesses processos, parece essencial. Isso é válido para a América Latina e para todo o Ocidente. A educação como processo facilitador de coesão social não só é objeto de nova regulação nas políticas que definem novas estruturas de funcionamento, como tem seus conteúdos transmutados por esses processos.

Muito já se discutiu sobre esse novo contexto. O processo de globalização e suas conseqüências para a educação têm sido exaustivamente debatidos. Trata-se de uma nova realidade, sem dúvida, porém não mais tão nova assim, apenas o suficiente para que ainda tenhamos pouco acúmulo de experiência que nos permita um pouco mais de estabilidade e previsão analítica. Boaventura de Sousa Santos procura assim descrever este contexto de novidade, em que as dimensões de espaço e tempo são geradoras de novas relações, resultando em uma difícil articulação entre o local e o global: 
O que há, pois, de novo na situação em que nos encontramos? Em primeiro lugar, a intensificação exponencial das relações transfronteiriças e as novas tecnologias de comunicação e de informação produziram alterações profundas nas escalas espaciais e temporais da acção social. As longas durações históricas das tendências seculares estão hoje mais do que nunca sujeitas ao tempo instantâneo dos mercados financeiros, ao regresso do passado supostamente superado sob a forma de violência intergrupal, ao curto-circuito dos ciclos de acção política por via da explosão das unidades de decisão. A turbulência nas escalas temporais é a contrapartida da turbulência nas escalas espaciais. O local é cada vez mais o outro lado do global e, vice-versa, o global é cada vez mais o outro lado do local. E o espaço nacional está a transformarse na instância de mediação entre o local e o global. Mas, acima de tudo, da explosão das escalas resulta tanto a interdependência como a disjunção. Nunca foi tão profundo o sentimento de desconexão e de exclusão em relação às transformações que marcam o espaço e o tempo do mundo. Por outras palavras, nunca tantos grupos estiveram tão ligados ao resto do mundo por via do isolamento, nunca tantos foram integrados por via do modo como são excluídos. (Santos, 2002, p. 2)

Roger Dale (2001), ao analisar a relação entre globalização e educação, procura demonstrar que a globalização é um conjunto de dispositivos político-econômicos, para a organização da economia global, conduzidos pela necessidade de manter o sistema capitalista, mais do que qualquer outro conjunto de valores. A adesão aos seus princípios é veiculada por meio da pressão econômica e da percepção e do interesse nacionais próprios de cada país. Neste sentido, sua abordagem diferencia-se de outras tantas que tratam essa relação como um reflexo da cultura ocidental, baseada cognitivamente em torno de um conjunto particular de valores que penetram em todas as regiōes da vida moderna.

Assim, poderíamos compreender essa globalização hegemônica de que trata Boaventura de Sousa Santos como um processo de desenvolvimento do capitalismo que tem imposto ao mundo um ritmo mais intenso de produção e reprodução da vida social. Quando esse autor destaca, como um segundo fator novo, a voracidade com que a globalização hegemônica tem devorado não só as promessas de progresso, de liberdade, de igualdade, de não-discriminação e de racionalidade, como também a própria idéia da luta por elas, está falando de um tipo de desenvolvimento e acumulação capitalista. Para Santos (2005), a regulação social hegemônica deixou de ser feita em nome de um projeto de futuro e, com isso, deslegitimou todos os projetos de futuro alternativos antes designados por projetos de 
Regulação das políticas educacionais na América Latina e suas conseqüências para...

emancipação social. Aqui nos caberia indagar se não seria a promessa ou o projeto de futuro para as populações destituídas das condições materiais de existência que foi comprometido, se é que em algum momento ele esteve contemplado. A euforia do nacional-desenvolvimentismo conseguiu contagiar, por algumas décadas, a maioria da população - refiro-me à realidade de alguns países latino-americanos que viveram esse processo a partir dos anos de 1940 - com a idéia de progresso técnico e evolução econômica, e, sobretudo, com a idéia de nação.

A grande pergunta de Boaventura de Sousa Santos é se seria possível unir o que a globalização hegemônica separa e separar o que essa globalização une? Indaga também esse autor se reside apenas nisso a globalização contra-hegemônica? E ainda, se seria possível contestar as formas de regulação social dominantes e, a partir daí, reinventar a emancipação social? Talvez esse autor se encontre com Jameson, quando nos coloca o que pode vir a ser a principal questão: "Se não será essa reinvenção apenas uma armadilha mais que a modernidade ocidental nos prepara no momento em que nos julgamos a sair dela?" (Santos, 2002, p. 3).

Bauman (1999, p. 16), discutindo também os efeitos da globalização sobre as dimensões de espaço e tempo, procura demonstrar que surge uma nova assimetria entre a natureza extraterritorial do poder e a contínua territorialidade da "vida como um todo" - assimetria que o poder agora desarraigado, capaz de se mudar de repente ou sem prévio aviso, é livre para explorar e abandonar as conseqüências dessa exploração. Para esse autor, livrar-se da responsabilidade pelas conseqüências é o ganho mais cobiçado e ansiado que a nova mobilidade propicia ao capital sem amarras locais, que flutua livremente. Os custos de se arcar com as conseqüências não precisam ser contabilizados no cálculo da "eficácia" dos investimentos. Com os espaços públicos removidos para além do alcance da vida localizada, as localidades vão perdendo a capacidade de gerar e negociar sentidos e tornam-se cada vez mais dependentes de açôes que dão e interpretam sentidos, que são ações que elas não controlam. Nas palavras desse autor, "ser local num mundo globalizado é sinal de privação e degradação social” (Bauman, 1999, p. 8).

\section{A nova regulação das políticas educativas}

Essa grande tensão entre as dimensões locais e globais, referida pelos autores anteriormente citados como característica do processo de 
globalização, tem forjado uma nova regulação das políticas educativas. As novas formas de gestão e financiamento da educação que tiveram sua emergência na década passada, nos anos de 1990, constituem medidas políticas e administrativas de regulação dos sistemas escolares. Na realidade, tais medidas, implantadas em contexto de reformas que muitas vezes extrapolam o setor educacional, surgem como supostas soluçôes técnicas e políticas para a resolução de problemas de ineficiência administrativa dos sistemas escolares ou da busca por racionalização dos recursos existentes para a ampliação do atendimento, vindo ainda acompanhadas da idéia de transparência (prestação de contas e demonstração de resultados) e de participação local. De uma maneira geral, têm acompanhado a tendência de retirar cada vez mais do Estado seu papel executor e transferir para a sociedade - esta muitas vezes traduzida de forma simplificada como o mercado - a responsabilidade pela gestão executora dos serviços, alterando a relação com o público atendido.

Observa-se, na literatura nacional e internacional sobre o tema da política e administração escolar, a evidência de certa generalização nos programas de reforma educacional da última década que focalizam a escola como unidade do sistema, transformando-a em núcleo da gestão e do planejamento. ${ }^{4}$ Programas em âmbito nacional que se remetem diretamente às escolas, sem a mediação dos órgãos intermediários do sistema, têm sido uma constante nas reformas implementadas nas últimas duas décadas, tanto no sentido de financiarem ações quanto no sentido de sua avaliação dos resultados. O Programa Dinheiro Direto na Escola (PDDE), no Brasil, é um exemplo desse tipo de iniciativa em nosso país, acompanhado de programas similares na Argentina, no Chile e em outros países latino-americanos. Tais iniciativas vêm associadas ao estímulo à administração por objetivos, ao incentivo à pedagogia de projetos, à cultura da eficiência e demonstração de resultados, conformando o que Ball (2002), criticamente, denomina a performatividade escolar. Nos países centrais, verifica-se essa mesma tendência, com ênfase na exigência de resultados e na transparência. ${ }^{5}$

Essa realidade anteriormente mencionada tem sido demonstrada na produção acadêmica mais recente no campo da política educacional. ${ }^{6} \mathrm{Ob}-$ serva-se que um número significativo de estudos e pesquisas, muitos publicados em forma de artigos, livros e capítulos de livros, tem trazido o debate sobre essas novas formas de regulação da educação no contexto atual de reforma do Estado, ainda que, no caso específico do Brasil, empreguem 
Regulação das políticas educacionais na América Latina e suas conseqüências para...

pouco este termo. A gama de estudos e pesquisas nesse campo, no que se refere à gestão - a tensão entre descentralização e centralização; autonomia financeira e administrativa e sistemas nacionais de avaliação; a autonomia pedagógica requerida das escolas e as prescrições curriculares, entre outros -, pode ser considerada correlata à problemática da regulação educacional. O grande número de trabalhos dessa natureza publicados nos últimos cinco anos revela a necessidade de compreensão de uma realidade contraditória, em constante mutação. Os fenômenos retratados de maneira parcelada nesses estudos apontam, ainda, a necessidade de novas abordagens que procurem compreender a complexidade dos fatores e processos que vêm alterando significativamente essa realidade.

A nova regulação das políticas educativas interfere na organização de todo o sistema escolar, passando por todas as mediações até a escola. Um redesenho da organização e gestão desses sistemas está sendo esboçado e há muita contradição nesse processo. Os sistemas escolares continuam a contribuir na regulação da sociedade, quer como agências formadoras de força de trabalho, quer como disciplinadores da população, papel que ganha relevância no que se refere aos pobres, em face das transformaçóes sociais atuais. Sendo assim, a função da escola regular não se restringe à qualificação para o trabalho formal, mas deve contemplar, ainda e sobretudo, a divisão do trabalho com a complexidade recente trazida pelo crescimento dos setores informais. Por tais razões, não se pode pensar em uma única orientação na regulação das políticas educacionais hoje em todo o mundo. Os programas de reforma que se propõem a organizar a educação básica, de caráter geral, com o papel de formar a força de trabalho adequada às exigências últimas do capitalismo, também objetivam disciplinar a pobreza. ${ }^{7}$

Assim, a educação pública compreendida como um direito social a que todos deveriam ter acesso, sendo ao mesmo tempo mecanismo de reprodução da força de trabalho, constitui-se em importante espaço de disputa. Neste sentido, é possível compreender o processo de recuperação das lutas dos trabalhadores da educação, por parte do Estado, envolvendo a gestão, a organização e o financiamento da educação, que acaba por forjar novos modelos de regulação das políticas educacionais, assentados na descentralização da execução e na centralização da formulação e do controle sobre os resultados. A participação local, mediante criação de conselhos de controle e acompanhamento de políticas sociais, a adoção de modelos de flexibilidade administrativa na gestão pública, bem como a descentralização financeira presente nos orçamentos públicos, 
apelam para as noções de autonomia e participação oriundas dos movimentos reivindicativos, ainda que os envolvidos sejam, a rigor, meros contribuintes ou assistidos.

A defesa da escola pública e gratuita para todos tornou-se um discurso hegemônico, portador de um falso consenso. As distinçóes entre projetos de escola pública e, conseqüentemente, programas educativos, que animaram um intenso debate nos primórdios do século $\mathrm{XX}$, já não encontram lugar nos debates políticos atuais. $\mathrm{O}$ imediatismo, característico das lutas políticas das maiorias desprovidas das condiçóes mínimas de sobrevivência, não comporta o esforço reflexivo e a perseguição de objetivos históricos.

Uma nova regulação nas políticas educacionais na América Latina

Como já mencionado, nos últimos anos o campo de pesquisa em política educacional tem trazido importantes contribuiçóes à compreensão do cenário em mudança no que diz respeito a uma nova regulação educativa, ainda que no Brasil tais contribuições não tenham adotado diretamente o conceito de regulação. Os estudos mais recentes sobre os processos de descentralização, privatização e autonomia no setor educacional demonstram a tensão entre regulação e desregulação das políticas educativas. Ou, ainda, o que Ball (2002) considera um processo de reregulamentação. Alguns autores vêm se debruçando sobre essas questôes no plano internacional, desenvolvendo importantes estudos e pesquisas que procuram compreender as mudanças nas formas de regulação na política educacional; dentre eles, os trabalhos de Barroso (2003; 2004), Lessard \& Tardif (2001; 2004) e Lessard (2004) merecem destaque.

Barroso (2003), com base em uma análise realizada a partir da seleção de seis estudos desenvolvidos em diferentes contextos geopolíticos, cria uma tipologia que contribui na compreensão do que poderia ser designado como a problemática emergente no domínio das políticas educativas em nível internacional. Os estudos os quais toma como referencia o autor foram desenvolvidos nos Estados Unidos, no Canadá, em diferentes países europeus e na Austrália e apresentam uma convergência na problemática sobre a evolução dos processos de regulação. Ele identifica, com base nas análises realizadas em diferentes realidades nacionais, três modelos de regulação que denomina: efeito contaminação, efeito hibridismo e efeito mosaico. 
Regulação das políticas educacionais na América Latina e suas conseqüências para...

A referência primordial do referido autor é o próprio projeto de investigação do qual participa, intitulado Reguledunetwork (Changes in regulation modes and social production of inequalities in educations systemas: an European comparison), que abrange Inglaterra, Bélgica (comunidade francesa), França, Hungria e Portugal. A tipologia desenvolvida por Barroso leva ainda em consideração outros estudos desenvolvidos em países periféricos.

$\mathrm{Na}$ sua tipologia, o modelo denominado contaminação seria aquele em que alguns países, por meio de funcionários e membros de governo, na busca por soluçôes rápidas, tendem a adotar, em seus sistemas educativos, soluções aplicadas em outras realidades nacionais. Têm sido recorrentes estudos e pesquisas sobre a realidade educativa dos países latino-americanos que demonstram a influência dos organismos internacionais pertencentes à ONU, mais expressivamente o Banco Mundial e o Banco Interamericano de Desenvolvimento (BID), na condução de programas educacionais nesses países, organismos que acabam por recomendar o mesmo modelo em distintas realidades nacionais. Alguns estudos têm inclusive demonstrado que muitos desses acordos, que envolvem financiamento em forma de empréstimos, muitas vezes a juros altos, são efetuados a partir de demandas geradas pelos próprios funcionários dos referidos organismos e por funcionários ligados aos governos contratantes. ${ }^{8}$ Alguns desses funcionários se revezam em postos que alternam entre os governos de seus países e assentos em diferentes organismos internacionais.

O modelo de hibridismo "resulta da sobreposição ou mestiçagem de diferentes lógicas, discursos e práticas na definição e acção de políticas, o que reforça o seu caráter ambíguo e compósito" (Barroso, 2003, p. 24-25). As diferentes interpretações de determinadas recomendações desses organismos internacionais, bem como de acordos firmados entre governos, constrangidos às vezes por suas dívidas e compromissos externos, exemplificam tal hibridismo. No caso brasileiro, nota-se com certa freqüência açóes resultantes de políticas traduzidas e adequadas à realidade nacional, como, por exemplo, a própria noção de educação básica que, no Brasil, difere do que a Conferência de Jomtien estabeleceu para os países do EFA, ${ }^{9}$ do qual o Brasil é membro.

O terceiro tipo que Barroso apresenta em sua classificação é o efeito mosaico, que "resulta do processo de construção dessas mesmas políticas que raramente atingem a globalidade dos sistemas escolares e que, na 
maior parte das vezes, resultam de medidas avulsas de derrogação das normas vigentes, visando a situações, públicos ou clientelas específicas" (Barroso, 2003, p. 25).

O que se observa é que esses autores que vêm se dedicando ao tema da regulação das políticas educativas procuram compreender se estamos em face de novas políticas de regulação que passam por diferentes formas de institucionalização, em que os ideais de livre mercado e de economia auto-organizadora das relaçôes sociais e comerciais - a mão invisível que contribui no autodisciplinamento do mercado - imperam, ou se estamos diante de uma nova organização nas relações entre Estado e sociedade em que os tradicionais papéis são revistos. Neste sentido, discutir o que tem sido a compreensão usual dos conceitos de público e privado, de estatal e mercantil torna-se indispensável.

Em texto mais recente, Barroso (2004), discutindo as transformações mais significativas da regulação das políticas de ação públicas em educação no quadro europeu, identifica aumento da regulação transnacional, hibridismo da regulação nacional e fragmentação da regulação local. Certamente, as análises desse autor, a despeito de focarem-se no contexto europeu, lançam luzes em outras realidades, como é o caso do Brasil e de outros países da América Latina, o que merece ser considerado, ainda que se tenha aqui as especificidades de uma regulação social tardia, como nos observa Sposati (2002).

Lessard \& Tardif $(2001 ; 2004)$, em estudos relativos à realidade canadense, com algumas referências ao contexto norte-americano, discutem o atual modelo de regulação das políticas educacionais e suas conseqüências para os trabalhadores docentes. Esses autores identificam quatro forças de mudanças nesse contexto: a orientação atual das políticas educativas; a transformação do papel do Estado; a evolução para uma lógica de mercado e as novas tecnologias de informação e de comunicação. Observam, a partir da leitura de numerosos trabalhos contemporâneos que tratam sobre o tema, que para o trabalho docente esses fenômenos, somados à massificação da educação e à burocratização dos sindicatos, têm trazido conseqüências ambíguas e contraditórias. Esses autores concentram a literatura em duas tendências de análise: por um lado, estudos que identificam um processo de proletarização e precarização da profissão docente e, por outro, os que percebem uma reestruturação do trabalho pedagógico e a emergência de uma nova identidade. 
Regulação das políticas educacionais na América Latina e suas conseqüências para...

Com o objetivo de apresentar uma reflexão sobre a evolução atual do ensino, com base em trabalhos empíricos por eles realizados sobre a profissão docente e em uma releitura de vários trabalhos contemporâneos, Lessard \& Tardif (2004) identificam na atualidade um movimento generalizado de reestruturação escolar ao qual alguns países estão submetidos. Tal movimento caracteriza-se pela descentralização de decisões e pela introdução de uma participação intensiva dos pais e da comunidade, dentro do espírito da gestão em parceria, responsabilização pelas decisōes, profissionalização do ensino e prescrição de um programa nacional comum, centrado sobre os saberes de base. No interior deste vasto movimento, os autores destacam quatro ingredientes particularmente importantes que induzem aos novos modos de regulação da educação: a tensão entre uma política educativa neoliberal e uma política humanistaigualitária; a transformação do papel do Estado; a ascensão de um modelo mercantil; e a mundialização e o desenvolvimento de tecnologias de informação e de comunicação.

A partir de tais referências, é possível identificar nas reformas educacionais mais recentes no Brasil e em alguns países da América Latina, tais como Argentina e Chile, processos similares de busca por novas formas de regulação educacional e perceber consequiências similares às apontadas pelos autores anteriormente referidos sobre o trabalho docente. Dentre esses processos, destacam-se a centralidade que os programas de reforma têm atribuído à administração escolar, elegendo a escola como núcleo do planejamento e da gestão; o financiamento per capita, presente no ensino fundamental no Brasil (FUNDEF, com a Lei n. 9.424/96) e no Chile, bem como na Argentina; a regularidade e ampliação dos exames nacionais de avaliação; a avaliação institucional e de desempenho (tema amplamente debatido hoje no Chile e na Argentina); e outros mecanismos de gestão escolares que insistem na participação da comunidade (sobretudo auxiliando nas questôes administrativas), bem como a proliferação de conselhos com funções consultivas.

Os trabalhadores docentes no centro das reformas educacionais: a defasagem entre o texto e o contexto

Muito se tem discutido sobre a centralidade dos professores, nos programas governamentais, como agentes responsáveis pela mudança nos contextos de reforma. São eles, em geral, considerados os principais res- 
ponsáveis pelo desempenho dos alunos, da escola e do sistema. Diante desse quadro, os professores vêem-se, muitas vezes, constrangidos a responsabilizarem-se pelo êxito ou insucesso dos programas de reforma, bem como a se vitimarem diante das precárias condiçóes objetivas para a realizaçãoo das suas novas tarefas.

O professor, diante das variadas funções que a escola pública assume, tem de responder a exigências que estão além de sua formação. Em contexto de demasiada pobreza, como é o caso dos países latino-americanos, os professores vêem-se obrigados a desempenhar funções que estão além da tarefa educativa, do ato de ensinar. São compelidos, em dadas circunstâncias, a assumirem os papéis de agente público, assistente social, enfermeiro, psicólogo, entre outros. Tais exigências contribuem para um sentimento de desprofissionalização, de perda de identidade profissional, de constatação de que ensinar às vezes não é o mais importante. Essa situação é ainda mais reforçada pelas estratégias de gestão já mencionadas, que apelam à participação comunitária e ao voluntariado, na promoção de uma educação para todos. Nesse contexto, identifica-se um processo de desqualificação e desvalorização sofrido pelos professores que tem provocado mudanças significativas em sua identidade. As reformas em curso tendem a retirar desses profissionais a autonomia, entendida como condição de participar da concepção e da organização de seu trabalho.

Algumas pesquisas recentes demonstram como esse quadro de mudanças trazidas com os programas de reformas educacionais das últimas décadas tem afetado significativamente a condição dos docentes latinoamericanos. Dentre esses estudos destaca-se um exaustivo trabalho, recentemente publicado (Cf. Fonseca, 1997; Cobarlán, 2002), sob a coordenação de Emílio Tenti Fanfani, que traz dados significativos de quatro realidades nacionais: Argentina, Brasil, Peru e Chile. Outro trabalho que merece destaque, neste caso um estudo específico sobre as novas formas de regulação do trabalho docente, ${ }^{10}$ é o de Alejandra Birgin, que, a despeito de estar centrado na experiência argentina, traz importantes contribuições à análise do tema para a realidade latino-americana.

Apesar das especificidades de cada país, explicada por tantos fatores tais como cultura, história, modelo de colonização e até mesmo a língua, observam-se muito mais semelhanças que diferenças entre os distintos contextos nacionais no que se refere à realidade educacional. Talvez isso explique a maneira quase padronizada com que os organismos internacionais pertencentes à ONU têm tratado esses países, buscando exercer, 
Regulação das políticas educacionais na América Latina e suas conseqüências para...

sem dúvida, influência sobre os novos desenhos de regulação social desses países por meio de suas orientações, extraídas de estudos e pesquisas produzidos por esses mesmos organismos, e por meio de outras formas de constrangimentos econômicos. ${ }^{11}$ Contudo, o que se observa é que, embora essas orientações sejam as mesmas para o subcontinente, resultam em diferentes processos de assimilação nos distintos países. Tais fatores podem ser atribuídos ao grau de mobilização do movimento social e em especial ao movimento sindical docente, às diferenças culturais e de constituição da identidade nacional desses países.

Neste sentido, vale mencionar duas pesquisas recentemente realizadas no contexto latino-americano, que trazem subsídio a essa interpretação. A primeira foi uma pesquisa realizada por uma equipe intersindical (Fanfani, 2005), ou seja, composta por representantes de sindicatos dos diferentes países objetos da pesquisa: Argentina, Brasil, Chile e Uruguai. Tal pesquisa buscou levantar o quadro educacional de cada um desses países a partir das principais mudanças ocorridas nos últimos anos. A partir da caracterização desse quadro de reformas, buscou destacar os impactos que tais reformas tiveram sobre as condições de trabalho e formação dos docentes, bem como sobre a organização sindical e a capacidade de resistência desses trabalhadores. Uma outra pesquisa que merece destaque é um levantamento realizado em 5 países latino-americanos: Argentina, Brasil, Peru, Equador e México, sobre os conflitos docentes ocorridos entre os anos de 1998 e 2003 . Foram produzidos uma cronologia dos principais protestos ocorridos em 18 países latino-americanos no período delimitado pela pesquisa e 5 relatórios nacionais (dos referidos países) abordando os diferentes tipos de protestos (e seus protagonistas) registrados no período, e analisando a natureza, as motivações e os desdobramentos de tais protestos, buscando assim compreender a origem desses conflitos (Birgin, 2000).

A partir das contribuições anteriormente referidas e de muitas outras, as quais, nos limites deste artigo, não seria possível mencionar, é possível perceber que o movimento de reformas que toma corpo nos países da América Latina nos anos de 1990, demarcando uma nova regulação das políticas educacionais, traz conseqüências significativas para a organização e a gestão escolares, resultando em uma reestruturação do trabalho docente, podendo alterar, inclusive, sua natureza e definição. $\mathrm{O}$ trabalho docente não pode mais ser definido apenas como atividade em sala de aula, ele agora compreende a gestão da escola, no que se refere à dedica- 
ção dos professores ao planejamento, à elaboração de projetos, à discussão coletiva do currículo e da avaliação. ${ }^{12}$

A flexibilidade, a descentralização, o respeito à diferença e o reconhecimento da alteridade, elementos da retórica pós-modernista e tão presentes na nova regulação educativa que toma a escola como locus do sistema e lugar por excelência da articulação entre o global e o local, exigem do trabalhador docente a capacidade de mobilizar-se nessas distintas dimensōes. Contraditoriamente, os professores vêem-se envolvidos em uma ideologia que cultiva e valoriza a diferença, a transdisciplinaridade, o trabalho coletivo, o desenvolvimento de competências e habilidades, mas continuam a ser contratados por meio de contratos individuais de trabalho, para lecionarem disciplinas específicas e remunerados por horaaula de 50 minutos.

Compreender, nesse conturbado contexto, até que ponto essas novas práticas são produtos ou produtoras de novas políticas públicas educacionais exige necessariamente que se discuta o papel dos trabalhadores docentes neste novo contexto de regulação.

\section{Considerações finais}

A educação e, sobretudo, a educação escolar permanecem como importante instrumento de regulação social, exercendo a gestão do trabalho e da pobreza. Contudo, as mudanças no modelo de regulação social passam também por alteraçōes nas formas de regulação das próprias políticas sociais e, no caso latino-americano, a política educacional vem sendo orientada como política compensatória, focalizada nos mais pobres. Nos limites deste artigo, o que se pode constatar é que as mudanças ocorridas no contexto político latino-americano, que estariam conformando uma nova regulação da política educacional, seguem uma tendência internacionalmente observada de centrar-se na performatividade da escola, o que tem trazido sérias conseqüências para os trabalhadores docentes, provocando uma reestruturação de seu trabalho em um cenário contraditório e ambivalente.

Tais constatações são carentes de maiores confrontações com a realidade e indicam-nos a necessidade de maiores pesquisas. Talvez pudéssemos dizer que a América Latina, hoje, está em face do que Barroso (2003) denomina de um processo de regulação de hibridismo, em que se combi- 
Regulação das políticas educacionais na América Latina e suas conseqüências para...

nam diferentes elementos trazidos por certa contaminação, considerando a forte influência que os organismos internacionais ligados à ONU têm tido na definição das políticas educacionais neste subcontinente, conforme já comentado, e as formulaçóes locais. Nestas, contudo, é inegável a participação dos movimentos sociais e dos processos políticos autóctones, além de elementos estruturais, manifestos nas diferentes culturas, que acabam por interferir de forma substantiva nos rumos das reformas educacionais em curso.

Contudo, essa nova regulação traz, inegavelmente, nova abordagem sobre o trabalho docente. A retórica pós-modernista chega às escolas por meio de um discurso que, a despeito da ausência de sustentação prática, tem criado um sentimento de inadequação e de dívida muito freqüente entre os professores. $\mathrm{O}$ fosso entre o discurso e as condiçôes materiais faz com que o trabalho coletivo seja reduzido muitas vezes à soma de trabalhos ou tarefas individuais e que outras noções, tão caras ao movimento social, não mais se somem à luta pela emancipação social, para recorrer à tensão destacada por Santos (2002). É neste contexto latinoamericano, em que a democratização da educação vem sendo confundida com a massificação do ensino, em que a política educacional é muitas vezes tomada por política social compensatória, que assistimos mais uma vez à importação de idéias fora do lugar. Diante de uma realidade tão etérea, tão global, em que cada tentativa de extrapolação para dimensões mais amplas é inibida pela atração em sentido contrário, exercida pelas condiçốes objetivas, o sentimento reinante é de que se está calçado com sapatos de chumbo, que nos obrigam a permanecermos tão locais.

\section{Recebido e aprovado em agosto de 2005.}

\section{Notas}

1. Baseio-me, para tal afirmação, em levantamento realizado no primeiro semestre deste ano em alguns portais e acervos latino-americanos (SCIELO, REDUC, CAPES, entre outros) com o objetivo de conhecer a literatura específica produzida sobre o tema na América Latina, em livros, capítulos de livros, artigos em periódicos, teses e dissertações.

2. Programa criado pelo governo federal, por meio da Medida Provisória n. 213, de 10 de setembro de 2004.

3. Os documentos produzidos para a educação na América Latina pelos organismos internacionais vinculados à ONU, tais como UNESCO, CEPAL, PREAL, trazem esse tom. Uma outra referência largamente conhecida é o Relatório da Comissão Européia para a Educação (Delors, 1998). 
4. A esse respeito, publiquei um estudo anterior que observava tal tendência nos documentos da CEPAl da década de 1960 e nos resultados da Conferência Mundial sobre Educação para Todos, de Jomtien, realizada em 1990; ver Oliveira (1997).

5. Cf. Lessard (2004), com relação à realidade canadense, e Barroso (2004), sobre a experiência dos países europeus.

6. Utilizo aqui, como referência para tal afirmação, revisão de literatura, em fase de conclusão, englobando 40 anos de produção bibliográfica sobre o tema. Essa revisão foi realizada no âmbito do projeto de pesquisa "Gestão escolar e trabalho docente" (CNPQ/FAPEMIG), sob minha coordenação.

7. Cf. Oliveira (2000). Refiro-me a minha tese de doutorado, defendida em 1999, na Usp, publicada em livro sob o título: Educação básica: gestão do trabalho e da pobreza.

8. Education for All: grupo criado no âmbito da UNESCO, composto pelos nove países mais pobres e populosos do mundo.

9. Sobre a influência desses organismos nos processos de reforma do Estado nos países latinoamericanos, ver Salama \& Valier (1997).

10. Las reformas educativas en los paises del cono sur: un balance crítico (CLACSO, 2005).

11. Estudio de los conflitos en los sistemas educativos de la región: agendas, actores, evolucion, manejo e desenlaces (LPP/UERJ/OREALC/UNESCO/SANTIAGO, 2004).

12. No caso do Brasil, ver especificamente os artigos 13 e 14 da LDB n. 9.394/96.

\section{Referências bibliográficas}

AGLIETA, M. Régulación y crisis del capitalismo. Mexico: Siglo Veintiuno, 1979.

BALL, S.J. Reformar escolas/reformar professores e os territórios da performatividade. Revista Portuguesa de Educação, Braga, v. 15, n. 2, 2002.

BAUMAN, Z. Globalização: as conseqüências humanas. Rio de Janeiro: Zahar, 1999.

BARROSO, J. A escola pública: regulação, desregulação e privatização. Porto: ASA, 2003.

BARROSO, J. Os novos modos de regulação das políticas educativas na Europa: da regulação do sistema a um sistema de regulações. Educação em Revista, Belo Horizonte, n. 39, 2004.

BIRGIN, A. La docência como trabajo: la construcción de nuevas pautas de inclusión y exclusión. In: Gentili, P.; Frigotto, G. (Comp.). La ciudadanía negada: políticas de exclusión en la educación y el trabajo. Buenos Aires: CLACSO, 2000.

Educ. Soc., Campinas, vol. 26, n. 92, p. 753-775, Especial - Out. 2005

Disponível em <http://www.cedes.unicamp.br> 
Regulação das políticas educacionais na América Latina e suas conseqüências para...

BRASIL. Lei no 9.394, de 20 de dezembro de 1996. Estabelece as diretrizes e bases da educação nacional. Diário Oficial da União. Brasília, DF, 23 dez. 1996a, p. 27894.

BRASIL. Lei no 9.424, de 24 de dezembro de 1996. Dispõe sobre o Fundo de Manutenção e Desenvolvimento do Ensino Fundamental e de Valorização do Magistério, na forma prevista no art. $60, \$ 7^{\circ}$, do Ato das Disposições Constitucionais Transitórias, e dá outras providências. Diário Oficial da União, Brasília, DF.

CASTEL, R. As metamorfoses da questão social: uma crônica da questão social. Petrópolis: Vozes, 1999.

COBARLÁN, M.A. El Banco Mundial, intervención y disciplinamiento: el caso argentino, enseñanzas para América Latina. Buenos Aires: Biblos, 2002.

DALE, R. Globalização e educação: demonstrando a existência de uma cultura educacional mundial comum ou localizando uma agenda globalmente estruturada para a educação. Educação, Sociedade \& Culturas, Porto, n. 16, p. 133-169, 2001.

DECLARAÇÃO mundial sobre educação para todos e plano de ação para satisfazer as necessidades básicas de aprendizagem. Nova York: UNICEF, 1990.

DELORS, J. Educação: um tesouro a descobrir. São Paulo: Cortez; Brasília, DF: MEC/UNESCO, 1998.

FANFANI, E.T. La condición docente. Buenos Aires: Siglo Veintiuno, 2005.

FONSECA, M. O Banco Mundial e a gestão da educação brasileira. In: OliveirA, D.A. (Org.). Gestão democrática da educação: desafios contemporâneos. 2. ed. Petrópolis: Vozes, 1997.

JAMESON, F. Modernidade singular: ensaio sobre a ontologia do presente. Rio de Janeiro: Civilização Brasileira, 2005.

LESSARD, C. L'obligation de resultats en éducation: de quoi s'agit-il?: le contexte québécois d'une demande sociale, une rhétorique du changement et une extension de la recherche. In: Lessard, C.; Meirieu, P. L'obligation de resultats en éducation. Québec: Université Laval, 2004. 
LESSARD, C.; TARDIF, M. Le renouvellement de la profession enseignante: tendances, enjeux et défis des années 2000. Education et Francofhonie, Montréal, v. 29, n. 1, 2001.

LESSARD, C.; TARDIF, M. Les transformations actuelles de l'enseignement: trois scénarios possibles dans l'évolution de la profession enseignante? In: LESSARD, C.; TARDIF, M. La profession d'enseignant aujourd'hui: évolutions, perspectives et enjeux internationaux. Québec: Université Laval, 2004.

OLIVEIRA, D.A. (Org.). Gestão democrática da educação: desafios contemporâneos. 2. ed. Petrópolis: Vozes, 1997.

OLIVEIRA, D.A. Educação básica: gestão do trabalho e da pobreza. Petrópolis: Vozes, 2000.

OLIVEIRA, D.A.; MELO, S.D. Estudio de los conflitos en los sistemas educativos de la región: agendas, actores, evolución, manejo e desenlaces. Santiago: LPP/UERJ/OREALC/UNESCO, 2004. (Relatório de estudo de caso do Brasil).

LAS REFORMAS educativas en los países del cono sur: un balance crítico. Buenos Aires: Clacso, 2005.

SALAMA, P.; VALIER, J. Pobrezas e desigualdades no Terceiro Mundo. São Paulo: Nobel, 1997.

SANTOS, B.S. As tensões da modernidade. Porto Alegre, 2002. Disponível em: <http://www.dhnet.org.br>. Acesso em: 2005.

SANTOS, B.S. (Org.). Trabalhar o mundo: os caminhos do novo internacionalismo operário. Rio de Janeiro: Civilização Brasileira, 2005.

SPOSATI, A. Regulação social tardia: característica das políticas sociais latino-americanas na passagem entre o segundo e o terceiro milênio. In: CONGRESO INTERNACIONAL DEL CLAD, 7., 2002, Lisboa. Anais... Lisboa, 2002. p. 8-11. 